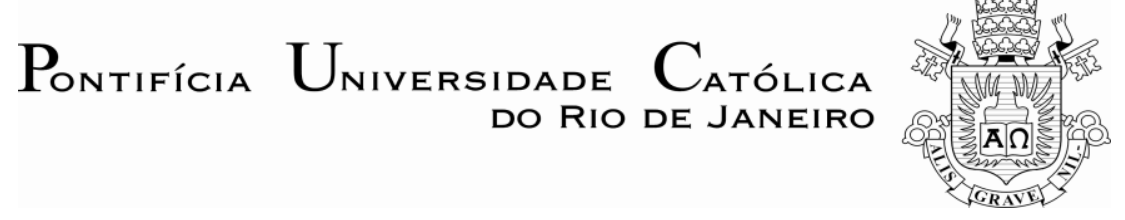

Theo Cotrim Martins

\title{
Leis de dividendo mínimo obrigatório protegem acionistas minoritários?
}

Dissertação de Mestrado

Dissertação apresentada ao Programa de PósGraduação em Economia da PUC-Rio como requisito parcial para obtenção do título de Mestre em Economia.

Orientador: Prof. Walter Novaes Filho 


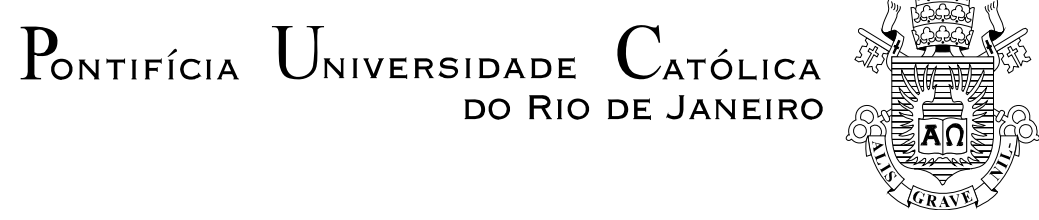

Theo Cotrim Martins

\section{Leis de dividendo mínimo obrigatório protegem acionistas minoritários?}

\section{Dissertação de Mestrado}

Dissertação apresentada como requisito parcial para obtenção do título de Mestre pelo Programa de PósGraduação em Economia do Departamento de Economia do Centro de Ciências Sociais da PUC-Rio. Aprovada pela Comissão Examinadora abaixo assinada.

Prof. Walter Novaes Filho

Orientador

Departamento de Economia - PUC-Rio

Prof. Marco Antonio Cesar Bonomo EPGE - Fundação Getúlio Vargas

Prof. Ricardo Pereira Câmara Leal COPPEAD - UFRJ

Profa. Mônica Herz

Coordenadora Setorial do Centro de Ciências Sociais - PUC Rio

Rio de Janeiro, 16 de Março de 2010 
Todos os direitos reservados. É proibida a reprodução total ou parcial do trabalho sem autorização do autor, do orientador e da universidade

Theo Cotrim Martins

Graduou-se em Engenharia Elétrica pela Faculdade de Engenharia Elétrica e de Computação (FEEC) da Universidade Estadual de Campinas (UNICAMP) em 2006.

Ficha Catalográfica

Martins, Theo Cotrim

Leis de dividendo mínimo obrigatório protegem acionistas acionistas minoritários? / Theo Cotrim Martins ; orientador: Walter Novaes Filho. - 2010.

51 f. : il. ; $30 \mathrm{~cm}$

Dissertação (Mestrado em Economia) - Pontifícia Universidade Católica do Rio de Janeiro, Rio de Janeiro, 2010.

Inclui bibliografia

1. Economia - Teses. 2. Dividendo mínimo obrigatório. 3. Proteção aos acionistas minoritários. 4. Custo de Financiamento. I. Novaes, Walter. II. Pontifícia Universidade Católica do Rio de Janeiro. Departamento de Economia. III. Título.

CDD: 330 


\section{Agradecimentos}

Ao meu orientador Professor Walter Novaes, pelo estímulo, apoio, parceria e, mais do que isso, por ter despertado em mim o interesse pela pesquisa.

Aos meus pais Iberê e Cinita pelo apoio em todas minhas decisões de vida. Agradeço também pelo investimento de longo prazo em meus estudos.

A todos os amigos e familiares que de uma forma ou de outra me estimularam ou me ajudaram.

Aos meus colegas e amigos da PUC-Rio. Em especial, agradeço ao Rafael Magri, pelas inúmeras discussões e sugestões propostas ao longo do trabalho.

Aos professores que participaram da banca examinadora.

A todos os professores e funcionários do Departamento pelos ensinamentos e pela ajuda.

À CAPES, ao Departamento de Economia da PUC-Rio e à PUC-Rio, pelos auxílios concedidos, sem os quais este trabalho não poderia ter sido realizado. 


\section{Resumo}

Martins, Theo Cotrim; Novaes Filho, Walter (Orientador). Leis de dividendo mínimo obrigatório protegem acionistas minoritários? Rio de Janeiro, 2010. 51p. Dissertação de Mestrado - Departamento de Economia, Pontifícia Universidade Católica do Rio de Janeiro.

Este trabalho mostra que as regras brasileiras de dividendos mínimos fazem com que a distribuição de proventos no Brasil seja alta relativamente aos Estados Unidos, apesar da fraca proteção oferecida pela lei das S.A. aos acionistas minoritários no Brasil. Ainda assim, subterfúgios legais permitem que $42 \%$ de uma ampla amostra de empresas não financeiras com ações listadas na Bovespa distribuem menos dividendos do que o previsto em estatuto. Tal retenção de ganhos poderia ser benéfica aos acionistas, visto que garante financiamento a novos projetos. Entretanto, dados de investimentos das empresas listadas na Bovespa mostram que este não parece ser o caso: à exceção de períodos com forte restrição ao crédito, a regra brasileira de dividendos mínimos protege os acionistas minoritários sem prejudicar a capacidade das firmas financiarem oportunidades de investimento.

\section{Palavras-chave}

Dividendo mínimo obrigatório; proteção aos acionistas minoritários; custo de financiamento. 


\section{Abstract}

Martins, Theo Cotrim; Novaes Filho, Walter (Advisor). Do mandatory dividend rules protect minority sharedholders? Rio de Janeiro, 2010. 51p. MSc. Dissertation - Departamento de Economia, Pontifícia Universidade Católica do Rio de Janeiro.

This paper shows that Brazil's mandatory dividend rules partly explain why its average dividend yield is higher than in the U.S. And yet, several Brazilian firms bypass the mandatory dividend rules. We show that $42 \%$ of a broad sample of nonfinancial firms with shares listed at Bovespa use legal loopholes to pay fewer dividends than the amount that their statutes call for. The data suggest that the main reason for these firms to bypass the dividend rules is not to ensure financing for new projects. Instead, lower dividend payments seem to pave the way for the controlling shareholders to dilute the cash-flow rights of minority shareholders. Thus, short of credit crunch, the Brazilian mandatory dividend rules do protect minority shareholders, without making harder for firms to finance investment opportunities.

\section{Keywords}

Mandatory minimum dividend; protection to minority shareholders; cost of external financing. 


\section{Sumário}

1 Introdução 11

2 Regras de Dividendo Mínimo Obrigatório 15

3 Comparações entre Brasil e Estados Unidos $\quad 19$

4 Dividendo Mínimo Obrigatório e Oportunidades de Investimento 23

5 Investimento e dividendo fora da crise de 2009

6 Conclusões $\quad 32$

7 Referências bibliográficas $\quad 34$

8 Tabelas 36 


\section{Lista de figuras}

Gráfico 1: Investimentos entre pagadores e não pagadores de dividendos.......29 


\section{Lista de tabelas}

Tabela 1 - Dividendo Mínimo Obrigatório definido em estatuto............................36

Tabela 2 - Dividendos previstos em estatuto vs efetivamente pago ...................37

Tabela 3 - Comparações entre diferentes grupos de empresas .................... 38

Tabela 4 - Utilização de reservas ................................................................ 39

Tabela 5 - Utilização dos diferentes tipos de reservas .....................................40

Tabela 6 - Estatísticas descritivas ............................................................... 41

Tabela 7 - Comparações no pagamento de dividendos: Brasil e EUA................42

Tabela 8 - Estatísticas descritivas da amostra ................................................. 44

Tabela 9 - Análise Multivariadas de Investimentos, antes e depois da crise ......45

Tabela 10 - Variação de investimentos, antes e depois da crise de 2008,

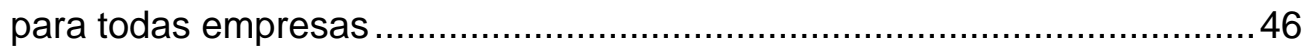

Tabela 11 - Variação de investimentos, antes e depois da crise, somente empresas de alto endividamento ............................................47

Tabela 12 - Variação em investimentos, ano a ano..........................................48

Tabela 13 - Variação de investimentos, ano a ano, somente para as firmas de alto endividamento............................................................................ 49

Tabela 14 - Descrição das variáveis utilizadas..................................................50 
"Rather than love, than money, than fame, give me truth."

Henry David Thoreau 